\title{
Nonlinear Damage Mechanics Approach in Investigating Cracks in Reinforced Concrete Flexural Members
}

\author{
Ahmad Salah Edeen Nassef ${ }^{1}$ \\ ${ }^{1}$ Fucalty of Engineering - Matria, Helwan University, Cairo, Egypt \\ Correspondence: Ahmad Salah Edeen Nassef, Fucalty of Engineering - Matria, Helwan University, Cairo, Egypt, \\ PO Box: 11718, Masaken Elhelmia Cairo, Egypt. Tel: 20-1016-433-771. E-mail: ahmad_nassef@hotmail.com
}

Received: April 20, 2016

Accepted: May 27, 2016

Online Published: July 4, 2016

doi:10.5539/mas.v10n10p62

URL: http://dx.doi.org/10.5539/mas.v10n10p62

\begin{abstract}
This paper was investigating cracks in reinforced concrete members subjected to pure bending using nonlinear damage mechanics approach. Concrete, steel and total damage variables were introduced and correlations were derived. Comparisons with different experimental and theoretical methods were executed, comparison between the proposed approach and different codes of practices were also executed. A parametric study was carried out for total damage variable considering both concrete cover and reinforcement ratio at different concrete damage variable.
\end{abstract}

Keywords: damage mechanics, damage variable, reinforced concrete, flexural, cracks

\section{Introduction}

Mechanical damage is the gradual process of mechanical deterioration that ultimately results in component failure. Fracture is an instance of substantial material damage typically associated with exposure to more extreme loading conditions. Damage mechanics is the study of material damage based on the introduction of damage variables and their evolution under the applied loading conditions. In the past few decades, the damage assessment in construction and industrial fields raised.

Bengt B. Broms (1964) developed a simple method for calculation of crack width and crack spacing in reinforced concrete members. The crack widths determined by this method were compared with test data obtained from flexural and tensile reinforced concrete members. Bengt B. Broms (1965) investigated theoretically and experimentally the factors affecting the formation of tensile cracks in reinforced concrete members, developed hypotheses for the prediction of crack width and crack spacing for flexural members. J. L. Lndoocns (1988) reviewed some practical damage growth equations for creep, fatigue, creep-fatigue interaction, ductile damage, and brittle damage and discussed the capabilities of Continuum Damage Mechanics to improve both the crack initiation and crack propagation predictive tools. Robins et al (2001) investigated the fracture of steel fiber reinforced sprayed concrete under flexural loading, with the aim of developing a stress-block model to predict flexural behavior in the form of a load-deflection response. Milan Jirásek (2004) explained the basic concepts of continuum damage mechanics and its nonlocal formulation with application to concrete. Using oneand two-dimensional examples, it was shown that a stress-strain law with softening postulated within the standard continuum theory. Jerzy Bobinski and Jacek Tejchman (2005) modelled concrete using a simple isotropic damage continuum model and presented finite element results on the behavior of concrete under plane strain conditions. Ziad N. Taqieddin (2008) modeled the behavior of RC members using the nonlinear finite element analysis (NFEA) . A thermodynamically consistent constitutive model for concrete that incorporates concrete-plasticity and fracture-energy-based continuum damage mechanics was presented. George Z. Voyiadjis and Peter I. Kattan (2008), (2012) examined various definitions of the damage variables and compared it. They gave special emphasis to a new damage variable that is defined in terms of the elastic stiffness of the material. Said M. Allam et al (2012) developed some building code equations, which used for the calculation of the crack width in reinforced concrete flexural members. Y. S. Upadhyaya and B. K. Sridhara (2012) predicted Continuum Damage Mechanics (CDM) approach to model the crack initiation life with a damage value and damage beyond the crack initiation phase by Fracture Mechanics in terms of crack size. Kent A. Harries et al (2012) presented a study of flexural crack widths of beams reinforced with high-strength ASTM A1035 reinforcing steel. Ashkan Saboori et al. (2015) presented an anisotropic damage mechanics model to 
describe the behavior and failure of concrete under biaxial fatigue loading, a strength softening function was proposed in order to address the reduction in the strength of concrete due to fatigue.

\section{Method}

\subsection{Nonlinear Damage Analysis of Reinforced Concrete Flexural Member}

Consider a beam of span $\mathrm{L}$ and cross sectional area $\mathrm{A}=\mathrm{b} \times \mathrm{h}$ was subjected to pure bending moment $\mathrm{M}$ as shown in Figure (1).
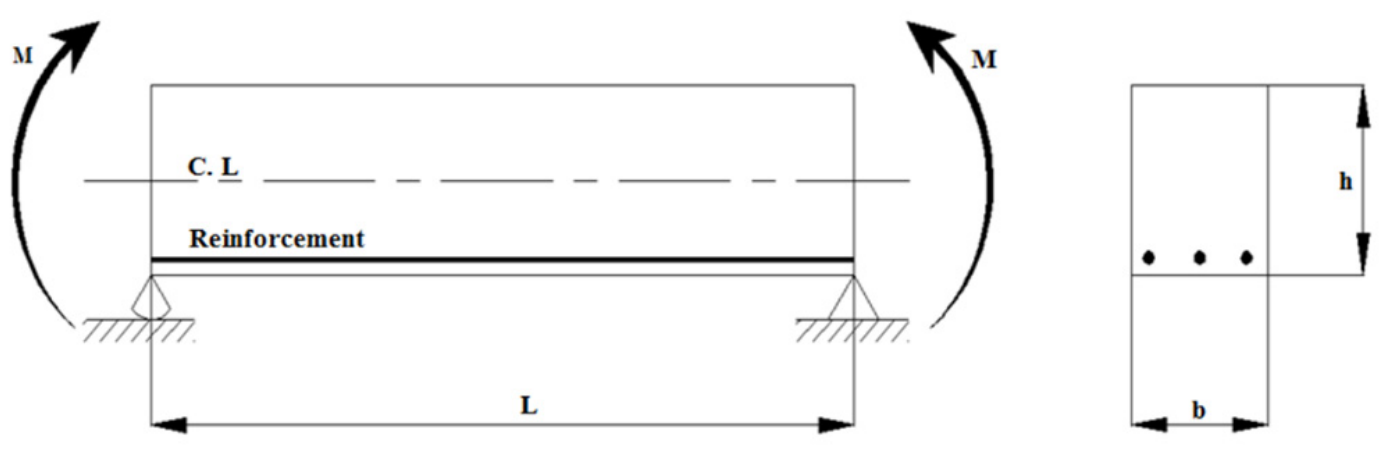

Figure (1) Geometry and Cross Section of Considered Beam

When the flexural member loaded with its bending capacity (ultimate moment), cracks will be formed and the damaged shape will be as shown in Figure (2).

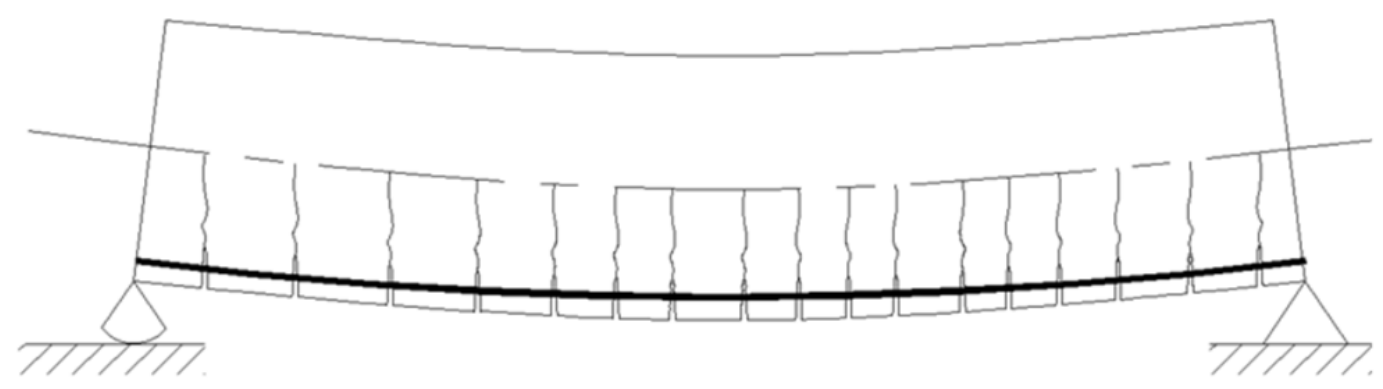

Figure 2. Damaged Shape

In order to use principle of damage mechanics, primary and secondary voids and cracks are removed to obtain the effective undamaged shape as shown in figure (3), where the cross sectional area will be $\bar{A}=b \times \bar{h}$. One should note that, for simplicity removing cracks and voids was modifying the depth only without the width.
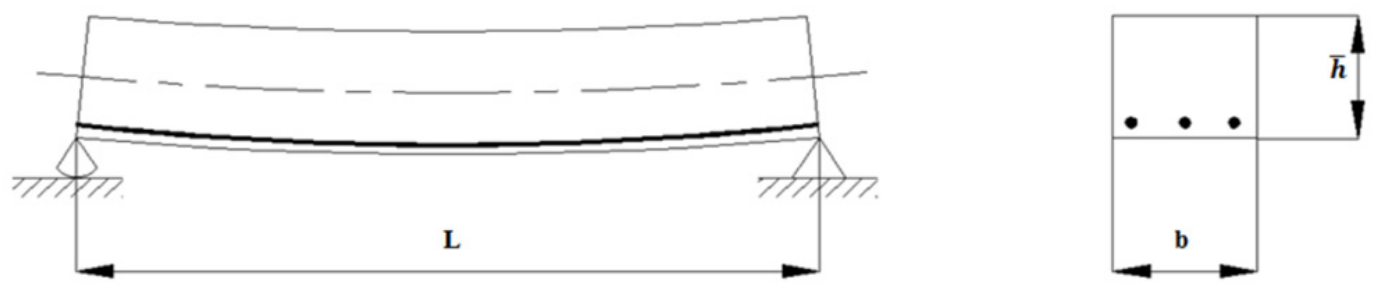

Figure 3. Effective Undamaged Shape

Bending stresses in the undamaged beam (before cracking) can be determined easily from: 


$$
\sigma=\frac{M}{S}
$$

Where:

$\sigma$ is the bending stress.

$M$ is the applied bending moment.

$S$ is the first moment of area.

Also the bending stress in the effective undamaged beam (after removing cracks and voids) can be determined from:

$$
\bar{\sigma}=\frac{M}{\bar{S}}
$$

Where:

$\bar{\sigma}$ is the bending stress in the effective undamaged beam.

$\bar{S}$ is the first moment of area for a cross section in the effective undamaged beam.

By using the definition of damage variable $(\ell)$, which, depending on the reduction of the elastic modulus:

$$
\ell=\frac{\bar{E}-E}{E}
$$

Where:

$E=\frac{\sigma}{\epsilon}$ is the elastic modulus.

$\bar{E}=\frac{\bar{\sigma}}{\bar{\epsilon}}$ is the effective elastic modulus.

$\epsilon$ is the strain in damage state.

$\bar{\epsilon}$ is the effective strain in the fictitious state (state of removing cracks and voids).

From equations (1), (2) and (3), one can deduce that:

$$
\ell=\frac{S \epsilon}{\bar{S} \bar{\epsilon}}-1
$$

By applying the hypothesis of equal strain energy in damaged case and fictitious case, one obtains:

$$
\frac{1}{2} \sigma \epsilon=\frac{1}{2} \bar{\sigma} \bar{\epsilon}
$$

From equations (1), (2) and (5), and substitution in equation (4):

$$
\ell=\frac{s^{2}}{\bar{S}^{2}}-1
$$

Equation (6) is considered as a novel expression for damage variable, and can be symbolized for reinforced concrete flexural member as:

$$
\ell_{t}=\frac{s^{2}}{\bar{s}^{2}}-1
$$

Where:

$\ell_{t}$ is the reinforced concrete damage variable.

Also, in the same way, one can introduce two damage variables:

$$
\begin{gathered}
\ell_{c}=\frac{s_{c}^{2}}{\bar{s}_{c}^{2}}-1 \\
\ell_{s}=\frac{s_{s}^{2}}{\bar{S}_{S}^{2}}-1
\end{gathered}
$$

Where: 
$\ell_{c}$ is the concrete damage variable.

$S_{c}$ is the first moment of area for concrete section.

$\bar{S}_{c}$ is the effective first moment of area for concrete section in fictitious state.

$\ell_{s}$ is the reinforcement steel damage variable.

$S_{S}$ is the first moment of area for reinforcement steel.

$\bar{S}_{s}$ is the effective first moment of area for reinforcement steel in fictitious state.

The reinforced concrete section is treated as a composite section, so one can find that:

1 - In damaged case:

$E I=E_{c} I_{c}+E_{s} I_{S}$

2 - In fictitious case:

$\bar{E} \bar{I}=\overline{E_{c}} \overline{I_{c}}+\overline{E_{s}} \bar{I}_{s}$

Where:

$E_{c}$ is the elastic modulus of concrete in the damaged case.

$E_{s}$ is the elastic modulus of steel in the damaged case.

$\overline{E_{c}}$ is the elastic modulus of concrete in the fictitious case.

$\overline{E_{S}}$ is the elastic modulus of steel in the fictitious case.

$I_{c}$ is the second moment of area for concrete section in damaged case.

$I_{S}$ is the second moment of area for reinforcement in damaged case.

$\overline{I_{c}}$ is the second moment of area for concrete section in fictitious case.

$\bar{I}_{S}$ is the second moment of area for reinforcement in fictitious case.

Dividing equation (10) by equation (9), one can obtain:

$$
\left(\ell_{t}+1\right) \frac{\bar{I}}{I}=\frac{1}{\left(\frac{I_{c}}{I_{C}}\right)\left(\frac{1}{\ell_{c}+1}\right)+\frac{E_{S} I_{S}}{E_{C} I_{C}}}+\frac{1}{\left(\frac{I_{S}}{I_{S}}\right)\left(\frac{1}{\ell_{S}+1}\right)+\frac{E_{C} I_{C}}{E_{S} I_{S}}}
$$

Assume that damage occurs only in concrete, then $\ell_{s}=0$ (i. e $\overline{E_{S}}=E_{S}$ ), and where the modular ratios in damaged case and fictitious case are $n=\frac{E_{s}}{E_{c}}, \bar{n}=\frac{\overline{E_{s}}}{\overline{E_{c}}}=\frac{E_{s}}{\overline{E_{c}}}$, then:

$$
\left(\ell_{t}+1\right) \frac{\bar{I}}{I}=\frac{1}{\left(\frac{I_{c}}{I_{c}}\right)\left(\frac{1}{\ell_{c}+1}\right)+\bar{n} \frac{I_{S}}{I_{C}}}+\frac{1}{\left(\frac{I_{s}}{I_{S}}\right)+\frac{1 I_{C}}{n \bar{I}_{S}}}
$$

After some manipulations:

$$
\begin{aligned}
& \sqrt{\left(\ell_{t}+1\right)}=\frac{h}{\bar{h}}\left(\frac{1}{\left(\frac{h}{\bar{h}}\right)\left(\frac{1}{\sqrt{\ell_{C}+1}}\right)+\bar{n} \frac{A_{S} \times\left(d-\frac{h}{2}\right)^{2}}{\overline{A_{C}} \times \frac{\bar{h}^{2}}{12}}}+\frac{1}{\left(\frac{\left(d-\frac{h}{2}\right)}{\left(\bar{d}-\frac{\bar{h}}{2}\right)}\right)+\frac{1 A_{\mathcal{C}} \times \frac{h^{2}}{12}}{{ }_{A_{S} \times\left(\bar{d}-\frac{\bar{h}}{2}\right)^{2}}}}\right) \\
& \text { Put } \rho=\frac{A_{s}}{b h} \text { and } \bar{\rho}=\frac{\overline{A_{s}}}{\overline{\bar{b}}}=\frac{A_{s}}{\overline{\bar{h}}}
\end{aligned}
$$

$\rho$ and $\bar{\rho}$ are reinforcement and effective reinforcement ratios.

Where, $A_{c}=b h-A_{s}$

Then:

$$
\frac{A_{c}}{A_{s}}=\frac{1-\rho}{\rho}
$$

In the same way: 


$$
\frac{\overline{A_{c}}}{A_{s}}=\frac{1-\bar{\rho}}{\bar{\rho}}
$$

By substitution from (14), (15) and (16), one can obtain:

$$
\sqrt{\left(\ell_{t}+1\right)}=\frac{h}{\bar{h}}\left(\frac{1}{\left(\frac{h}{\bar{h}}\right)\left(\frac{1}{\sqrt{\ell_{c}+1}}\right)+\bar{n} \frac{\bar{\rho}\left(d-\frac{h}{1-\bar{\rho}}\right)^{2}}{\frac{\bar{h}^{2}}{12}}}+\frac{1}{\left(\frac{\left(d-\frac{h}{2}\right)}{\left(\bar{d}-\frac{\bar{h}}{2}\right)}\right)+\frac{11-\rho \frac{h^{2}}{n \rho}\left(\bar{d}-\frac{\bar{h}}{2}\right)^{2}}{n}}\right)
$$

The above relation shows that he total damage variable of reinforced concrete depends on the damage variable of concrete, reinforcement ratio and concrete cover.

\subsection{Problem Solution}

1 - Specify the compressive strength of concrete $\left(f_{c}\right)$, elastic modulus of concrete in damaged case $\left(E_{c}=\right.$ $\left.4700 \sqrt{f_{c}} " M P a^{\prime}\right)$ and elastic modulus of steel $\left(E_{s}\right)$.

2 - Determine the dimensions of the proposed flexural member $(b, h, L)$.

3 - Use practical values of concrete damage variable $\left(\ell_{c}\right)$.

4 - Find the modular ration in a damaged case $(n)$ and modular ratio in the fictitious case $(\bar{n})$, Also find the depth of the cross section of fictitious case $(\bar{h})$ in case of concrete damage only.

5 - Get the reinforcement ratio in a damaged case $(\rho)$ and fictitious case $(\bar{\rho})$.

6 - Calculate the total damage variable for reinforced concrete $\left(\ell_{t}\right)$.

7 - Find the depth of the cross section of fictitious case $(\bar{h})$ in case of reinforced concrete damage which should be less than the depth of the cross section of fictitious case for case of concrete damage only.

8 - Calculate the volume of voids and cracks by subtracting the volume of effective flexural member from the volume of the damaged flexural member.

\subsection{Flexural Members Cracks Propagation According to Codes of Practices}

\subsubsection{Eurocode2 1992-1 (2001)}

For calculating the crack width in flexural member, one can follow:

$$
W_{k}=S_{r, \max .}\left(\varepsilon_{s m}-\varepsilon_{c m}\right)
$$

Where:

$W_{k}$ is the design crack width.

$S_{r, \text { max }}$ is the maximum crack spacing.

$\varepsilon_{s m}$ is the main steel strain.

$\varepsilon_{c m}$ is the main concrete strain.

$$
\left(\varepsilon_{s m}-\varepsilon_{c m}\right)=\frac{\left(f_{s}-k_{t}\left(\frac{f_{c t e f f}\left(1+2 \rho_{\text {eff }}\right)}{\rho_{\text {eff }}}\right)\right)}{E_{S}} \geq 0.6 \frac{f_{S}}{E_{S}}
$$

$f_{s}$ is the stress in tension reinforcement.

$k_{t}$ is the factor expressing the duration of loading.

$f_{\text {cteff }}$ is the mean value of effective tensile strength of the concrete.

$$
\rho_{\text {eff }}=\frac{A_{s}}{A_{\text {ceff }}}
$$

$A_{S}$ is the area of steel.

$A_{\text {ceff }}$ effective tension area of concrete.

$c$ is the concrete cover.

$$
S_{r, \max .}=3.4 c+0.425 k_{1} k_{2} \emptyset / \rho_{\text {eff }}
$$

$k_{1}$ is the coefficient of bond properties. 
$k_{2}$ is the coefficient of strain distribution.

$\emptyset$ is the bar diameter.

\subsubsection{ACI 318}

ACI proposed equation for crack width of flexural member is:

$W_{\text {max }}=0.011 \beta f_{s} \sqrt[3]{d_{c} A_{o}} * 10^{-3}$

$\beta=\frac{h-x}{d-x}$ is the ratio of the distance between neutral axis and extreme tension face.

$A_{o}=\frac{A_{e}}{n_{b}}$ is the area of the concrete surrounding reinforcement bar.

$A_{e}$ is effective area of concrete in tension

$n_{b}$ number of tension reinforcing bars.

$d_{c}$ is the distance measured from the centroid of tensile steel to the extreme tensioned fiber.

\subsubsection{British Standard BS 8110}

According to BS 8110 the crack width can be calculated from:

$$
W=\frac{3 a_{c r} \varepsilon_{m}}{1+2\left(\frac{a_{r}-c_{\min }}{h-x}\right)}
$$

Where:

$a_{c r}$ is the distance from the point considered to the surface of the nearest longitudinal bar.

$\varepsilon_{m}$ is the average strain at the level where cracking is being considered.

$c_{\min }$ is the minimum concrete cover.

$x$ is the depth of neutral axis and $h$ is the member depth.

\subsubsection{Oh and Kang (1987) Formula For Crack Width}

Oh and Kang (1987) suggested the following equation:

$$
W=\emptyset a_{o}\left(\varepsilon_{s}-0.0002\right) R
$$

Where:

$$
\begin{aligned}
& a_{o}=159\left(\frac{t_{b}}{h-x}\right)^{4.5}+2.83\left(\frac{A_{o}}{A_{s 1}}\right)^{1 / 3} \\
& R=(h-x) /(d-x)
\end{aligned}
$$

$A_{o}=\frac{A_{e}}{n_{b}}$ is the area of the concrete surrounding reinforcement bar.

$A_{e}=b h_{1}, h_{1}$ is the depth of equivalent area.

$$
h_{1}=\frac{(h-x)^{3}}{3(d-x)^{2}}
$$

$x$ is the depth of neutral axis and $h$ is the member depth.

\section{Analysis and Results}

The proposed was verified depending on experimental work introduced by Bengt B. Broms (1964) and (1965), where crack width and crack spacing were measured within the pure moment region for the flexural members between the load points. Crack widths were measured to the nearest $0.001 \mathrm{in}$. by a 50 -power hand microscope. The crack spacing was measured by a steel ruler to the nearest $0.1 \mathrm{inch}$. The beam specimens were tested in a standard 400,000 Ib. Baldwin Universal Testing Machine. The following Table (1) shows the detail of the cross sections of the used specimens. 
Table 1. Cross Sections Details of Concerned Specimen by Bengt B. Broms

Specimen Code

B-R5

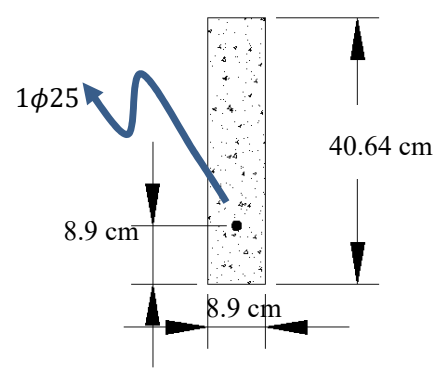

B-R6

The beams were loaded either at the third or quarter points through a pair of $20 \mathrm{ft}$. reaction beams attached to the head of the testing machine. The free span length of the members was $12.0 \mathrm{ft}$. Rollers with a diameter of $2.0 \mathrm{in}$. were used at the loads and the support points. The applied load was increased in ten to fifteen increments until the maximum load was reached. The average crack width visible at the surface of flexural members can be calculated if it is assumed that the elongation (or contraction) of the concrete between two tensile cracks is negligible. If this assumption is made, then the product of the number of tensile cracks $N$ at the level of the reinforcement within the length $L$ times the average crack width $W_{\text {avg }}$ (the average crack width) is equal to the total elongation of the reinforcement as expressed by the equation:

$$
W_{\text {avg }} \times N=\varepsilon_{s} \times L
$$


Where $\varepsilon_{s}$ is the average steel strain. Since the number of tensile cracks within the length $L$ equal to $L / S_{\text {avg }}$, where $S_{\text {avg }}$ is the average crack spacing, Equation (18) can be rewritten as:

$$
W_{\text {avg }}=\varepsilon_{s} \times S_{\text {avg }}
$$

From the observation that the average crack spacing $S_{\text {avg }}$ is approximately equal to twice the distance $t$ (concrete cover), the average crack width at the level of the reinforcement can be calculated as:

$$
W_{\text {avg }}=\varepsilon_{s} \times 2 t
$$

Also, Makhlouf and Malhas reported results of tests on 11 beams reinforced with high strength deformed bars. The crack width was recorded. The specimens consisted of 3 wide beams of $600 \mathrm{~mm}$ width, $400 \mathrm{~mm}$ depth and clear concrete cover $=50 \mathrm{~mm}$. The experimental specimens were tested under a load level of $80-110 \%$ of service load. Group "B" aimed to assess the magnitude of crack widths in full-size beams. The following Table (2) shows the detail of the cross sections of the used specimens.

Table 2. Cross Sections Details of Concerned Specimen by Makhlouf and Malhas

Specimen Code

Table 3 shows the obtained results of the proposed approach Considering both Bengt B. Broms and Makhlouf specimens. These results can be used to calculate the crack width (W) and compare it with that obtained experimentally by Bengt B. Broms and Makhlouf, as shown in Table 4 and Table 5. Also comparison with theoretical method and equations of codes of practices was made where, Bengt B. Broms's calculations were compared with those obtained from the new approach, as shown in Table 4, and comparisons with ACI 318, Eurocode 2, BS8110 and Oh and Kang method were shown in Table 6. 
Table 3. Results of Proposed Approach

\begin{tabular}{|c|c|c|c|c|c|c|c|c|c|c|}
\hline \multirow{8}{*}{$\begin{array}{l}\text { Specimen } \\
\text { Code }\end{array}$} & \multirow[b]{3}{*}{ Concrete } & \multicolumn{2}{|l|}{ Elastic } & \multicolumn{7}{|l|}{ Elastic } \\
\hline & & Modulus & & Modulus & & & & Damage & & \\
\hline & & of & Daniage & of & Liasil & Modular & Modular & Variable & Effective & Volume \\
\hline & Strength & Concrete & c & Concrete & (1) & Ratio for & Ratio for & for & Depth of & of Voids \\
\hline & $\left(f_{c}\right)$ & for & & for & O & Damaged & Fictitious & Reinforced & Fictitious & and \\
\hline & & Damaged & Concrete & Fictitious & $\left(E_{s}\right)$ & Case $(n)$ & Case $(\overline{\boldsymbol{n}})$ & Concrete & Case $(\overline{\boldsymbol{h}})$ & Cracks \\
\hline & & Case $\left(E_{c}\right)$ & 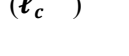 & Case $\left(\overline{\boldsymbol{E}_{\boldsymbol{c}}}\right)$ & GPa & & & $\left(\boldsymbol{\ell}_{t}\right)$ & & \\
\hline & & "MPa" & & "MPa" & & & & & & \\
\hline B-R1-1 & 31.44 & 26353.55 & 0.00425 & 26465.552 & 194.432 & 7.377 & 7.346 & 0.003019 & 36.1702 & 32.2556 \\
\hline B-R1-2 & 29.16 & 25380 & 0.00394 & 25479.997 & 194.432 & 7.661 & 7.630 & 0.0027657 & 36.1726 & 29.7413 \\
\hline B-R4 & 35.7 & 28588.98 & 0.005 & 28731.928 & 182.228 & 6.374 & 6.342 & 0.003695 & 36.1639 & 39.1339 \\
\hline B-R5 & 35.7 & 26640.75 & 0.005 & 26773.954 & 194.432 & 7.298 & 7.261 & 0.004001 & 40.5973 & 46.2553 \\
\hline B-R6 & 24.821 & 23415.72 & 0.0017 & 23455.525 & 194.432 & 8.303 & 8.289 & 0.001161 & 36.1820 & 58.4287 \\
\hline G1 & 40 & 29725.41 & 0.004375 & 29855.458 & 200 & 6.728 & 6.698 & 0.003935 & 39.9597 & 120.6701 \\
\hline G2 & 40 & 29725.41 & 0.004375 & 29855.458 & 200 & 6.728 & 6.698 & 0.003731 & 39.9603 & 118.8363 \\
\hline G3 & 40 & 29725.41 & 0.004375 & 29855.458 & 200 & 6.728 & 6.698 & 0.003456 & 39.9599 & 120.2194 \\
\hline
\end{tabular}

Table 4. Comparison of Cracks Width from Proposed Approach and Brom's Work

\begin{tabular}{cccccc}
\hline Specimen Code & $W_{\text {new Approach }}$ & $W_{\text {Brom's Experiment }}$ & $W_{\text {Brom's Calculations }}$ & $\frac{W_{\text {new Approach }}}{W_{\text {Brom's Experiment }}}$ & $\frac{W_{\text {Brom's Calculations }}}{W_{\text {Brom's Experiment }}}$ \\
\hline B-R1-1 & 0.01586 & 0.01651 & 0.028638 & 0.96 & 1.73 \\
\hline B-R1-2 & 0.01338 & 0.01333 & 0.019177 & 1.00 & 1.43 \\
\hline B-R4 & 0.010752 & 0.011747 & 0.021717 & 0.92 & 1.84 \\
\hline B-R5 & 0.021572 & 0.0254 & 0.036271 & 0.85 & 1.42 \\
\hline B-R6 & 0.006838 & 0.00625 & 0.008564 & 1.09 & 1.37 \\
\hline
\end{tabular}

Table 4 shows a good agreement between experimental results of Brom and the new approach results, while Brom's calculations did not give the same agreement as the experiment.

Table 5. Comparison of Cracks Width from Proposed Approach and Maklouf's Work

\begin{tabular}{cccc}
\hline Specimen Code & $W_{\text {new Approach }}$ & $W_{\text {Makhlouf's Experiment }}$ & $\frac{\boldsymbol{W}_{\text {new Approach }}}{\boldsymbol{W}_{\text {Makhlouf's Experiment }}}$ \\
\hline G1 & 0.0135 & 0.011 & 1.227 \\
\hline G2 & 0.0138 & 0.015 & 0.92 \\
\hline G3 & 0.01487 & 0.018 & 0.8261 \\
\hline
\end{tabular}

Table 5 shows a good agreement between experimental results of Maklouf and the new approach results. 
Table 6. Comparison of Cracks Width from Some Codes of Practice and New Proposed Approach

\begin{tabular}{ccccccccc}
\hline Specimen Code & $W_{\text {Eurocode2 } 2}$ & $\frac{W_{\text {new Approach }}}{W_{\text {Eurocode } 2}}$ & $W_{B S 8110}$ & $\frac{W_{\text {new Approach }}}{W_{B S 8110}}$ & $W_{\text {ACI } 318}$ & $\frac{W_{\text {new Approach }}}{W_{\text {ACI } 318}}$ & $W_{\text {Oh-Kang }}$ & $\frac{W_{\text {new Approach }}}{W_{\text {Oh-Kang }}}$ \\
\hline G1 & 0.018 & 0.75 & 0.009 & 1.5 & 0.02 & 0.675 & 0.015 & 0.9 \\
\hline G2 & 0.019 & 0.726 & 0.013 & 1.061 & 0.024 & 0.575 & 0.019 & 0.726316 \\
\hline G3 & 0.016 & 0.929 & 0.012 & 1.239 & 0.021 & 0.708 & 0.017 & 0.874706 \\
\hline
\end{tabular}

Table 6 shows a good agreement between the new approach and codes of practice, whereas the percentage of reinforcement increases, the agreement increase, Also there is a good agreement between the new approach and $\mathrm{Oh}$ - Kang method.

\section{Parametric Study}

In this parametric study, the total damage variable of the reinforced concrete $\left(\ell_{t}\right)$ was studied with concern of many variables like concrete cover and reinforcement ratio at different concrete damage variables $\left(\ell_{t}\right)$.

Figure 4 shows the relation between concrete cover and total reinforced concrete damage variable $\left(\ell_{t}\right)$ at different concrete damage variable $\left(\ell_{c}\right)$ and states that the total reinforced concrete damage variable $\left(\ell_{t}\right)$ increases as the concrete cover increases. The rate of increase affected by the concrete damage variable, where the rate increases as the concrete damage variable increases.

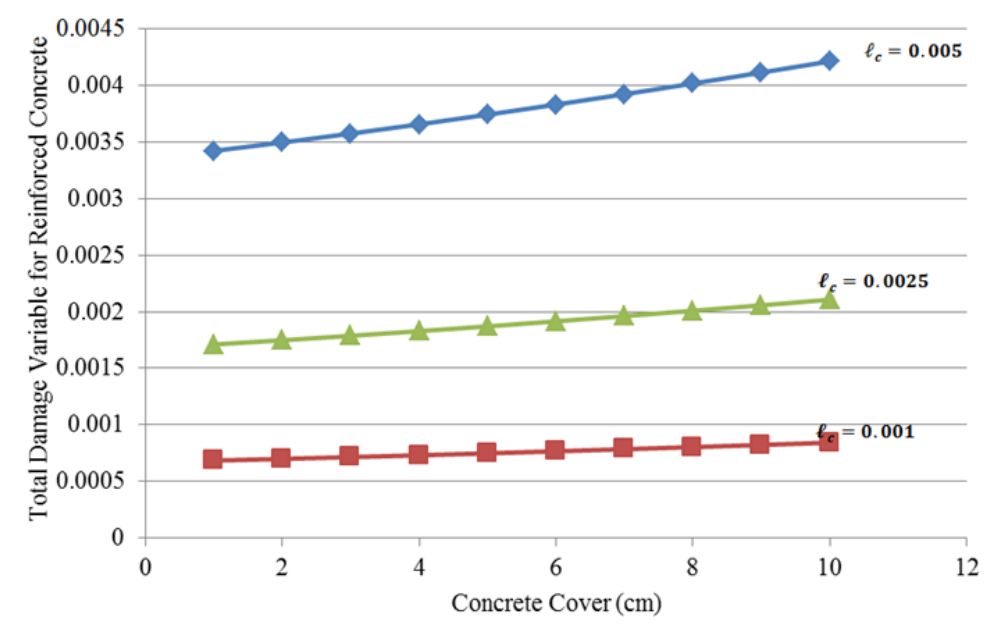

Figure 4. Effect of Concrete Cover on Total Reinforced Concrete Damage Variable

Also Figure 5 shows the relation between the reinforcement ratio and total reinforced concrete damage variable $\left(\ell_{t}\right)$ at different concrete damage variable $\left(\ell_{c}\right)$ and states that the total reinforced concrete damage variable $\left(\ell_{t}\right)$ decreases as the reinforcement ratio increases. The rate of decrease affected by the concrete damage variable, where the rate increases as the concrete damage variable increases. 


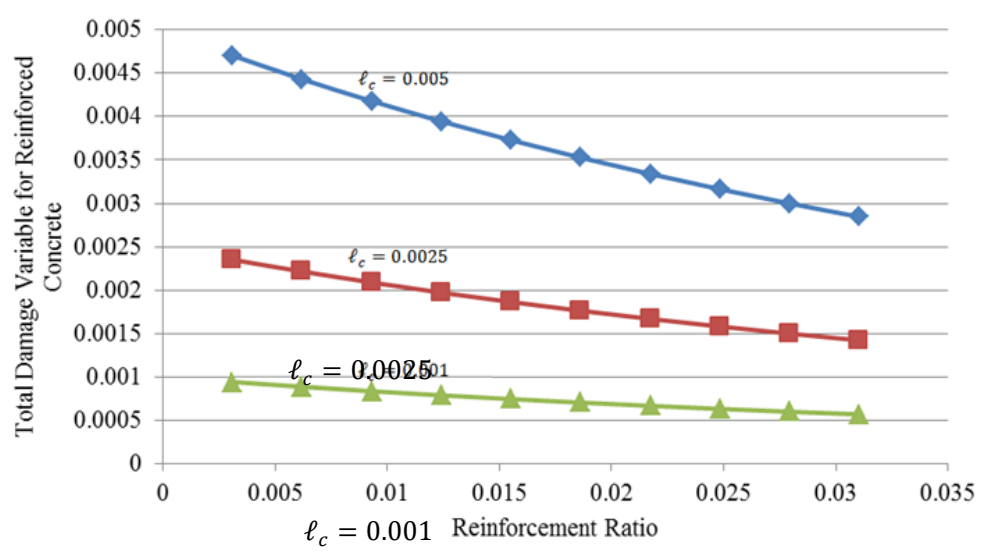

Figure 5. Effect of Reinforcement Ratio on Total Reinforced Concrete Damage Variable

\section{Conclusion}

From the results presented in this paper and comparison that made with both different codes of practices an experimental work and from the parametric study executed, one can conclude that:

- $\quad$ Proposed damage mechanics approach gives a good result in investigating cracks in flexural members, and can be used to calculate the cracks and voids volume, then crack width can be obtained.

- The total reinforced concrete damage variable increases as the concrete cover increases.

- The rate of increase of total reinforced concrete damage variable, with the increase of concrete cover, increases as the concrete damage variable increases.

- The total reinforced concrete damage variable decreases as the reinforcement ratio increases.

- The rate of decrease of total reinforced concrete damage variable, with the increase of reinforcement ratio, increases as the concrete damage variable increases.

6. Notation

$a_{c r}$ is the distance from the point considered to the surface of the nearest longitudinal bar.

$A_{c e f f}$ effective tension area of concrete.

$A_{e}$ is effective area of concrete in tension

$A_{o}$ is the area of concrete surrounding reinforcement bar.

$A_{s}$ is the area of steel.

$\beta$ is the ratio of the distance between neutral axis and extreme tension face.

$c$ is the concrete cover.

$d_{c}$ is the distance measured from the centroid of tensile steel to the extreme tensioned

fiber.

$E$ is the elastic modulus.

$E_{c}$ is the elastic modulus of concrete in the damaged case.

$E_{s}$ is the elastic modulus of steel in the damaged case.

$\bar{E}$ is the effective elastic modulus.

$\overline{E_{c}}$ is the elastic modulus of concrete in the fictitious case.

$\overline{E_{S}}$ is the elastic modulus of steel in the fictitious case.

$\epsilon$ is the strain in damage state.

$\bar{\epsilon}$ is the effective strain in fictitious state (state of removing cracks and voids).

$\varepsilon_{s m}$ is the main steel strain.

$\varepsilon_{c m}$ is the main concrete strain.

$\varepsilon_{m}$ is the average strain at the level where cracking is being considered. 
$f_{s}$ is the stress in tension reinforcement.

$f_{\text {cteff }}$ is the mean value of tensile strength of the concrete effective.

$h_{1}$ is the depth of equivalent area.

$I_{c}$ is the second moment of area for concrete section in damaged case.

$I_{S}$ is the second moment of area for reinforcement in damaged case.

$\bar{I}_{c}$ is the second moment of area for concrete section in fictitious case.

$\bar{I}_{s}$ is the second moment of area for reinforcement in fictitious case.

$k_{t}$ is the factor expressing the duration of loading.

$k_{1}$ is the coefficient of bond properties.

$k_{2}$ is the coefficient of strain distribution.

$\ell_{c}$ is the concrete damage variable.

$\ell_{s}$ is the reinforcement steel damage variable.

$\ell_{t}$ is the reinforced concrete damage variable.

$M$ is the applied bending moment.

$n_{b}$ number of tension reinforcing bars.

$\rho$ is reinforcement ratio.

$\bar{\rho}$ is the effective reinforcement ratio.

$S$ is the first moment of area

$S_{c}$ is the first moment of area for concrete section.

$S_{r, \text { max. }}$ is the maximum crack spacing.

$S_{S}$ is the first moment of area for reinforcement steel.

$\bar{S}$ is the first moment of area for a cross section in the effective undamaged beam.

$\bar{S}_{c}$ is the effective first moment of area for concrete section in fictitious state.

$\bar{S}_{s}$ is the effective first moment of area for reinforcement steel in fictitious state.

$\sigma$ is the bending stress.

$\bar{\sigma}$ is the bending stress in the effective undamaged beam.

$W_{k}$ is the design crack width.

$x$ is the depth of neutral axis and $h$ is the member depth.

$\emptyset$ is the bar diameter.

\section{References}

Ashkan, S., Siamak, Y., \& Denver, T. (2015). Anisotropic Damage Mechanics Modeling of Concrete under Biaxial Fatigue Loading. Open Journal of Civil Engineering, 5, 8-16.

Bengt, B. B. (1964). Crack Width and Crack Spacing in Reinforced Concrete Members. Report No. 311, School of Civil Engineering, Cornell University, Ithaca.

Bengt, B. B. (1965). Crack Width and Crack Spacing in Reinforced Concrete Members. Journal Of The American Concrete Institute, 62(10), 1237-1255.

Building Code Requirements for Reinforced Concrete, ACI 318-08 and Commentary ACI 318R-08, American Concrete Institute, Detroit, 2008.

Eurocode 2: Design of Concrete Structures - Part 1: General Rules and Rules for Buildings 1992-1, European Committee for Standardization, October 2001, Belgium.

George, V., \& Peter, I. K. (2012). A New Class of Damage Variables in Continuum Damage Mechanics. Journal on Engineering Material and Technology, 134(2), 21016- (10 pages).

George, Z., Voyiadjis, P., \& Kattan, I. (2008). A Comparative Study of Damage Variables in Continuum Damage Mechanics. International Journal of Damage Mechanics, 18(4), 315-340. 
Jerzy, B., \& Jacek, T. (2005). Modelling of Concrete Behaviour with a Non-Local Continuum Damage Approach. Archives of Hydro-Engineering and Environmental Mechanics, 52(3), 243-263.

Kent, A. H., Bahram, M., Shahrooz, M. A., \& Amir, S. (2012). Flexural Crack Widths in Concrete Girders with High-Strength Reinforcement. Journal of Bridge Engineering, 17(5), 804-812.

Lndoocns, J. L. (1988). Continuum Damage Mechanics: Part II - Damage Growth, Crack Initiation, and Crack Growth. Journal of Applied Mechanics, 55, 65-72.

Milan, J. (2004). Non-Local Damage Mechanics with Application to Concrete. Failure Degradation and Instabilities, 8, $683-707$.

Oh, B. H., Kang, Y. J. (1987). New formulas for maximum crack width and crack spacing in reinforced concrete flexural members. ACI Structural Journal, 84(2), 103-112.

Robins, P. J., Austin, S. A., \& Jones, P. A. (2001). Flexural Strain And Crack Width Measurement Of Steel Fiber Reinforced Concrete By Optical Grid And Electrical Gauge Methods. Cement And Concrete Research, 31(5), 719-729.

Said, M. A., Mohie, S. S., Gehad, E. R., \& Amal, S. H. (2012). Crack width evaluation for flexural RC members. Alexandria Engineering Journal, 51, 211-220.

Structural Use of Concrete, Part 2 (1998). Code of Practice for Special Circumstances BS 8110: Part 2: 1997. British Standard Institution, London.

Upadhyaya, Y. S., \& Sridhara, B. K. (2012). Fatigue Crack Initiation and Propagation Life Prediction of Materials", International Conference on Mechanical, Electronics and Mechatronics Engineering (ICMEME'2012) March 17-18, 2012 Bangkok.

Ziad, N. T. (2008). Elasto-Plastic and Damage Modeling of Reinforced Concrete. Ph. D Thesis, Faculty of the Louisiana State University and Agricultural and Mechanical College.

\section{Copyrights}

Copyright for this article is retained by the author(s), with first publication rights granted to the journal.

This is an open-access article distributed under the terms and conditions of the Creative Commons Attribution license (http://creativecommons.org/licenses/by/3.0/). 